\title{
Examining Pre-service Teachers' Instructional Strategies for Technological Pedagogical Content Knowledge via Video-conferencing
}

\author{
Hsiu-Jen Cheng \\ Kaohsiung Normal University
}

Hong Zhan

Embry-Riddle Aeronautical University

\begin{abstract}
This action research observes instructional strategies and appropriateness of the strategies that pre-service teachers have applied during their training based on the Technological Pedagogical Content Knowledge (TPACK) training model. Participants include 14 pre-service teachers who were enrolled in a Distance Education training course in Taiwan. During the course, pre-service teachers were trained to develop teaching skills based on the TPACK training model and applied their skills in video-conferencing teaching which involved 14 American students who were learning Mandarin Chinese as a Foreign Language (CFL) in an intermediate level course in the United States. Data were collected via screen recordings of online teaching, pre-service teachers' lesson plans, and instructional PowerPoint presentations. The results revealed in the content analysis that the CFL pre-service teachers applied four instructional strategies including using body language, graphic and pictures, animations, and text-based input to enhance understanding of the content. These instructional strategies were relatively simple and easy to use in the online teaching environment; however, overusing multimedia may cause instructional obstacles. This study suggests that when training pre-service teachers to use technologies, it is more important to train pre-service teachers to develop abilities that link technology tools with instructional goals.
\end{abstract}

Keywords: pedagogical strategies and models for e-learning, foreign language teacher training via video-conferencing, Technological Pedagogical Content Knowledge (TPACK), teaching and learning of CFL

\section{Introduction}

During the last few decades of technology development, teacher training on the effective use of technology in the classroom has been a focus in education.
However, existing studies have indicated that teacher training programs still have not yet fully prepared teachers for the effective use of technology (Brown \& Warschauer, 2006; Cantu, 2000; Kay, 2006; Koehler \& Mishra, 2009). A critical reason for this unsatisfactory 
finding is the lack of clear understanding of how to integrate technology appropriately into instructional design. Studies conclude that many language pre-service teachers do have the problem of utilizing technologies in teaching, thus leading to a lower level of teaching efficiency. Yurdakul's study in 2011 revealed that pre-service teachers "had a lower level of competence in use of technological concept and in the observations of students' development" (p. 33). Kumar and Vigil's (2011) survey results also indicate that improved digital technology skills do not guarantee pre-service teachers' competence of integrating technology into practice. Clearly, instructional design with rich technologies does not definitely guarantee effective instruction if the teachers do not carefully consider how each type of technology can help reach teaching/learning objectives.

Teacher training is insufficient when a training program only offers instruction of technological knowledge and isolates it from content and pedagogy. Instead of focusing solely on technologies, teacher educators need to help pre-service teachers develop a range of abilities to apply technological skills into content teaching with appropriate pedagogy. This skill set is called the Technological Pedagogical Content Knowledge (TPACK) (Koehler \& Mishra, 2005). During the TPACK training process, teacher trainers should assist pre-service teachers in transferring their TPACK knowledge into instructional design. In other words, instructional strategies that preservice teachers apply to the classroom should reflect their comprehensive understanding of integrated roles of technology, content, and pedagogy in teaching and learning. Therefore, an effective training program design should contain two consecutive components: (1) training on using technology techniques and (2) training on application of technology techniques in practice. Kay
(2006) listed strategies that appear in the literature that have been applied to prepare pre-service teachers for technology-based instruction. Many researchers also showed great interest on designing a model to foster pre-service teachers' TPACK development (Angeli \& Valanides, 2009; Koehler \& Mishra, 2005). However, few of the studies discussed instructional strategies that preservice teachers adopted during the training period and how these teachers transferred their TPACK into instruction.

Based on the related literature, this study conducted a semester-long teacher training to help CFL pre-service teachers in a southern Taiwan university develop their instructional strategies as reflected in the TPACK training model. The training in this study employed six training strategies: multimedia, singlecourse, modeling, collaboration, field-based, and mentor teachers. During the training, the pre-service teachers immediately practiced their instructional strategies in teaching Chinese as CFL via video-conferencing. The video-conferencing field experiences allowed the pre-service teachers to self-exam and to reflect on their integrated instructional skills suggested in the TPACK. The purposes of the study were to find out within the TPACK model what instructional strategies pre-service teachers used and whether those strategies were appropriate or not.

\section{Literature Review}

To fulfill the purpose of the study, literature associated with TPACK, teacher training strategies, and teaching with video-conferencing technology are addressed in this section.

\subsection{TPACK}

Recent studies on instructional technology training for pre-service teachers indicate that the lack of content-area relevance and 
inadequate transfer of technology skills to instructional strategies were the biggest weakness in technology training. These studies suggest that teacher educators need to prepare pre-service teachers for integrating different media into instructional settings (such as coursework, materials, and lessons) in more appropriate ways (Kumar \& Vigil, 2011; Sutton, 2011). These notions are supported with TPACK, a teacher knowledge that provides the best solution for authentic technology integration problems as advocated by Koehler and Mishra $(2005,2009)$.
TPACK was an updated version of Shulman's (1986) PCK (Pedagogical Content Knowledge), which states that a teacher's knowledge should include subject matter knowledge, pedagogical knowledge, and curricular knowledge. In the TPACK framework, teachers' TPACK knowledge is a complex interplay of three-dimensional knowledge: Technology Knowledge (TK), Pedagogy Knowledge (PK), and Content Knowledge (CK). In addition, this framework also includes four components: TCK, TPK, PCK, and TPACK (see Figure 1).

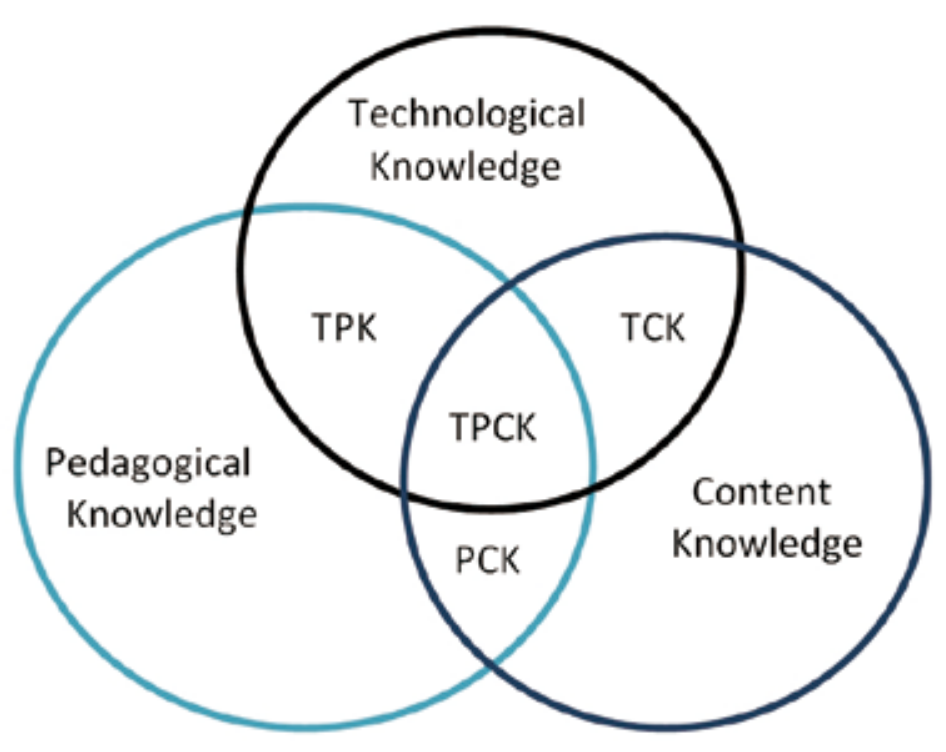

Figure 1. TPACK framework

(1) TCK (Technological Content Knowledge): knowledge of using technology with different learning subjects.

(2) TPK (Technological Pedagogical Knowledge): knowledge of using technology with different teaching methods.
(3) PCK (Pedagogical Content Knowledge): knowledge of subject-oriented teaching methods.

(4) TPACK (Technological Pedagogical Content Knowledge): knowledge of using technology with different teaching methods in accordance with subject content. 
Technology refers to analog and digital technologies, but recent studies mostly focus on digital technologies. Technology knowledge, defined by Koehler and Mishra (2009), is the Fluency of Information Technology (FIT) beyond the traditional definition of computer literacy. Digital technologies carry their own properties, strengths, and constraints, so that certain technology may perfectly match with some specific tasks, but not with others. Therefore, a teacher who knows the technology properties can adopt proper digital tools into the curriculum (Koehler \& Mishra, 2009).

TPACK knowledge is a guide for teacher educators to train future teachers. A teacher with TPACK knowledge knows technology broadly, distinguishes the strengths and constraints of digital tools, and applies them to the course design appropriately. Studies (Jang \& Chen, 2010; Koh, 2011) proposed that when providing technological training to preservice teachers, the training on integrating technology and pedagogy to teach a specific discipline should also be provided. If teacher training isolates any of these three dimensions, the training may not be effective to help teachers teach the content of a discipline with appropriate technology integration into a sound pedagogy.

\subsection{Teacher Training Strategies in Previous Studies}

Studies (Brzycki \& Dudt, 2005; Sutton, 2011) indicated that teacher training programs were not effective to prepare pre-service teachers to utilize computers in teaching with a sound pedagogy; therefore, how to introduce technology integration to pre-service teachers becomes a crucial issue in teacher education. Various strategies for this type of training have been addressed in previous studies. The most inclusive report on strategies were presented by Kay
(2006) who identified ten strategies: integrating technology in all courses, using multimedia, training in a single technology course, modeling how to use technology, collaborating among preservice teachers, practicing technology in the field, offering mini-workshops, improving access to digital resources, focusing on relationship between pre-service teachers and mentor teachers, and focusing on education faculty attitude and perceptions.

Among these ten strategies, modeling, collaboration, field-based, and mentor teacher strategies seem to be effective ones for teacher educators to create better training environments that allow pre-service teachers to experience the authentic and hands-on activities. Modeling strategy requires teacher trainers to demonstrate how to use technology into the classroom. Studies (Fleming, Motamedi, \& May, 2007) concluded that the more technology integration demonstrations or hands-on activities that pre-service teachers obtained, the more confidence they developed in using instructional technology skills. Collaboration means establishing the partnership among universities or public schools. The ultimate goal of such a strategy was to provide authentic practice and additional assistance for pre-service teachers in educational settings (Fry \& Bryant, 2006; Voithofer, 2005). Field-based strategy was highly recommended by ISTE/NACTE, and it was suggested that this strategy should be used in cooperation with other strategies to prepare pre-service teachers' readiness of technology integration (Alger \& Kopcha, 2011; Dawson, 2006). Mentor teachers strategy was conducted primarily in conjunction with the collaboration strategy (Fry \& Bryant, 2006; Kenny, 2009; Voithofer, 2005), and mentor teachers plays a critical role in developing preservice teachers' professional knowledge. This strategy is highly recommended to adopt in pre-service teacher training program. 
Strategies such as integrating technology, multimedia, single course, and workshops are recommended to be used along with other strategies. Integrating technology in other courses in a teacher training program promoted pre-service teachers' confidence of using technology skills when dealing with authentic problem-based tasks (Voithofer, 2005). Single course training often offers training on commonly used computer software or resources to all pre-service teachers (Wang, 2012). Multimedia strategy should be incorporated with different resources to develop pre-service teachers' knowledge such as digital storytelling (McKnight, Hoban, \& Nielsen, 2011), 3D computer graphics (Goodson-Espy, Lynch-Davis, Schram, \& Quickenton, 2010), or model instruction such as case-based instruction to increase preservice teachers' technology knowledge (Baker, 2005). Workshops (Teclehaimanot \& Lamb, 2005) were implemented to assist pre-service teachers in key areas with other strategies such as modeling, multimedia, and so on. Those strategies are meaningful when adopted along with other strategies and reinforce the efficiency of the training outcome.

Strategies including improving faculty members' attitudes toward using technology may increase pre-service teachers' use of computers in education settings, but more research is needed to bridge the connections between the two factors. Last, all of the strategies will not be able to be implemented if pre-service teachers do not have access to a variety of digital resources, including hardware and software (Dawson, 2008; Vermillion, Young \& Hannafin, 2007). An effective pre-service teacher training program not only helps pre-service teachers' increase their technological knowledge, but also gives them more opportunities to incorporate technological knowledge with pedagogical and content knowledge. To reach this goal, more than one strategy should be taken into consideration in pre-service teacher training (Kay, 2006). Following this suggestion, this current study adopted six teaching training strategies (including single-course, multimedia, modeling, collaboration, fieldbased, and mentor teachers) to train preservice teachers to develop their teaching skills so as to best reflect the results of the training with the TPACK training model.

\subsection{Teaching Foreign Languages with Video- conferencing Technologies}

Researchers have found that videoconferencing can provide learners with optimal environments for teaching foreign languages beyond what the traditional classroom learning can afford. Traditional teacher training in the classroom cannot often provide real contexts in which pre-service teachers can immediately apply their knowledge in practice ( $\mathrm{Wu}$, et al., 2011a). Instead, many studies of teaching foreign languages via video-conferencing tools have found that video-conferencing tools could be used to increase authentic interaction between language learners and native speakers, promote communicative competence, and develop knowledge of different cultures (Wu, Yen, \& Marek, 2011a; Wu \& Marek, 2011b). $\mathrm{n}$ addition, compared with other types of technologies (e.g., blogs, email, or discussion boards), video-conferencing allows the "reallife" interaction during which users can use non-verbal means of communication including gestures, facial expressions, and objects to further deliver and understand information. These non-verbal means of communication means are considered important in teaching foreign languages and culture (McCafferty \& Ahmed, 2000). This current study adopted video-conferencing technology as an instructional platform where pre-service teachers experienced authentic interactions with CFL learners in the United States. 


\section{Research Methodology}

Action research is used to look for best solutions in real situations. The type of action research applied in this study was educational action research through which professional educators became involved in authentic problem-solving (O'Brien, 2001). The training conducted in the distance education course in Taiwan implemented six strategies including single-course, multimedia, modeling, collaboration, field-based, and mentor teachers. The ultimate goal of the course was to help pre-service teachers acquire technology skills, and then apply their technology skills to online teaching during the training period. Therefore, action research was chosen to examine the teachers' instructional strategies and the appropriateness of the strategies that pre-service teachers applied during their training with the TPACK training model.

\subsection{Research Questions}

Specific research questions investigated in this research are:

1. What instructional strategies did preservice teachers use to transfer TPACK into practice?

2. Were those strategies pedagogically appropriate to teaching CFL lessons online via a video-conferencing platform?

\subsection{Research Context}

Teaching practice and learning opportunities are needed in Chinese language education. In Taiwan, teaching practice opportunities for CFL pre-service teachers are very limited and this has become a common issue for most of the CFL pre-service teacher training programs (Cheng, Zhan, \& Tsai, 2010). The alternative solution for many CFL programs is to offer distance education courses or projects to allow pre-service teachers to earn teaching experience. Therefore, nowadays with the support of video-conferencing technology, the partnership between the teacher training programs and student learning programs has become very popular.

In this action research, the master level teacher training program is located in a national southern university in Taiwan. The CFL teacher training program was established in 2003 and currently it enrolls thirty students. Most of the students take two years to finish coursework. They are required to earn 100 hours in one-toone practicum before they graduate. Students have to search for internships on their own from Mandarin learning centers in higher education institutions. There are limited offers and it is very competitive. Therefore, if they have experienced an authentic teaching environment and trained on how to use technology in the instruction, it is easier for them to earn the practicum opportunities. Distance Education is one of the courses that offer cross-continental online teaching opportunities. Students in this class are trained with the TPACK model. The American CFL learners that participated in this study were second year college students enrolled in a southwestern university in the United States. The American university is located in a rural area where students do not have the chance to learn Chinese language and culture locally. The video-conferencing platform connected these CFL teachers and students in different continents to meet their different needs of teaching and learning Chinese.

Based on the TPACK teacher training model, this action research specially incorporated six strategies during the training process to help pre-service teachers develop integrated knowledge of technology, content, and pedagogy. The six training strategies include single-course, multimedia, modeling, collaboration, field-based, and mentor teachers. 
The CFL teacher training course in the study was a graduate level course Distance Education (single course). This training course included two components: training on using multimedia tools and field teaching practice via the videoconferencing tool. The researchers, as mentor teachers, were the course instructors in Taiwan and in the United States who provided the pre-service teachers with suggestions and comments regarding technology integration, teaching content, and pedagogy.

The instructor from Taiwan demonstrated and modeled the technology or multimedia tools that could be incorporated in course design and teaching strategies. Pre-service teachers who participated in this research were paired to design lesson plans and assisted each other in field practice, the video-conferencing lessons. A total of five lessons were offered by each pre-service teacher. Lessons were designed by themes: introduction, student life, hobbies and pastime, part-time job, and school system in Taiwan. During the training period, the different multimedia tools were also introduced and demonstrated. Hands-on activities were included.

The video-conferencing tool adopted in this research is a free version of WizIQ. WizIQ has the features that most video-conferencing platforms offer (e.g., audio, video, text, file uploading, video sharing, and whiteboard) for interactive online instruction.

(1) Whiteboard supports PowerPoint, PDF files, and Web pages, and also it offers drawing and writing tools. It keeps the animations when using PowerPoint presentations. This is not a common feature of the whiteboard compared to other commercial video-conferencing tool. It is an important feature for a language class. Unfortunately, the text boxes do not support Chinese characters when typing, but if the text is copied from other applications and is pasted the text to the whiteboard, the Chinese characters will show.

(2) Chatting/texting box located at the right side bar of WizIQ supports Chinese characters, so that users can type Chinese.

(3) YouTube videos can be shared in WizIQ. WizIQ connects with YouTube. To show a YouTube video, the users first upload the videos to YouTube and then show the videos in WizIQ through links to the YouTube videos.

(4) Recording live sessions. The WizIQ system can automatically record each class session. Users can also download or view the recorded sessions in breakout rooms. However, this function is only activated for premium members.

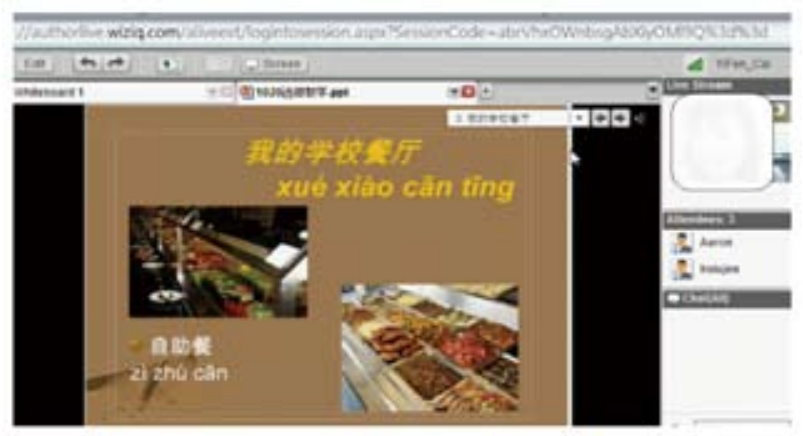

Figure 2. WizIQ platform 


\subsubsection{Sampling and Subjects.}

This action research was conducted from September to November in 2011. A convenient sampling strategy was chosen because the study was conducted in a naturalistic environment in which a real teacher training class and a real Chinese language class were taught. Fourteen graduate students enrolled in a Distance Education course were selected as the participants in this research. The participants were paired up with 14 Chinese learners who were studying Chinese in an intermediate level class in southwestern university in the United States.
Table 1 illustrates the biographic information of the 14 participants, among which three are males and eight are females. Most of them had very limited experience in teaching Chinese as a foreign language. Most of the participants taught as private tutors, and two of them (T5 and T13) did not have any teaching experience. A few of them (T4 and T9) have classroom teaching experience. In terms of nationalities, this group of teachers is very international because some of them are nonnative speakers of Chinese, but their Chinese proficiency was closely to native-like Chinese.

Table 1. The Background of Subjects

\begin{tabular}{ccccc}
\hline ID & Gender & $\begin{array}{c}\text { Teaching Experiences as } \\
\text { Tutors (hours) }\end{array}$ & $\begin{array}{c}\text { Classroom Teaching } \\
\text { (months) }\end{array}$ & $\begin{array}{c}\text { Native } \\
\text { Language }\end{array}$ \\
\hline T1 & F & 100 & & Chinese \\
T2 & F & 36 & & Chinese \\
T3 & F & 30 & 7 & Thai \\
T4 & F & 100 & & Chinese \\
T5 & F & 0 & Chinese \\
T6 & F & 120 & French \\
T7 & M & 100 & & French \\
T8 & M & 600 & Chinese \\
T9 & F & & Chinese \\
T10 & F & 100 & Thai \\
T11 & F & 60 & Chinese \\
T12 & F & 40 & Chinese \\
T13 & F & 0 & Chinese \\
T14 & M & 100 & Chinese \\
\hline
\end{tabular}




\subsubsection{Teacher Training Model: Three Phases.}

Following the TPACK model and action research procedures, this training provided technological, pedagogical, and content training elements in three phases: (1) lesson plans and techniques, (2) review and revision, and (3) online teaching, observation, and reflection (see Figure 3). The first two phases were conducted in a regular face-to-face classroom, and the last phase was conducted online in WizIQ (see Figures 3 and 4). The three training phrases were employed when pre-service teachers taught five different lessons online; therefore, pre-service teachers experienced the circle of training five times (see Figure 4) when they taught the content related to self-introduction, student life, hobbies and pastime, part-time jobs, and the school system.

In Phase One, lesson plans and techniques, technological, pedagogical, and content knowledge began to develop. The mentor teachers demonstrated the different features of each digital tool the pre-service teachers needed to learn (technological knowledge-TK), and presented examples with explanations of instructional design principles. At this stage, technological skills and multimedia resources including WizIQ functions, screen recording, creation of flash videos, online resources incorporations, as well as instructional design principles of teaching with technologies were demonstrated and modeled by the trainer teachers. TPK (Technological Pedagogical Knowledge) and TCK (Technological Content Knowledge) were presented. After watching the demonstrations, pre-service teachers worked in pairs to design their own lesson plans that aimed to allow the pre-service teachers to reflect upon their TPK and TCK.

In Phase Two, review and revision, technological, pedagogical, and content knowledge were enhanced through observations, presentations, and revisions. Pre-service teachers were paired up to present and display their teaching lessons on the five topics that they would teach every other week. Phase two training was also a stage of presenting their TPK (Technological Pedagogical Knowledge), TCK (Technological Content knowledge), and PCK (Pedagogical Content Knowledge). The teacher trainers and pre-service teachers provided comments and suggestions on the instructional design and technology uses. Good instructional design with pedagogically sound technology integration was recommended as examples; inappropriate designs were revised following given suggestions.

In Phase Three, online teaching, observation, and reflections, pre-service teachers delivered online instruction which reflected their technological, pedagogical, and content knowledge. This was also the time when pre-service teachers transferred their TPACK to the classroom. The teacher trainers observed the classes and provided comments and suggestions immediately after each online session. Pre-service teachers wrote reflections upon their own teaching through reviewing the screen recording of their teaching. Each instance of teaching reinforced their technical and pedagogical knowledge.



Figure 3. Three phases of the training model 


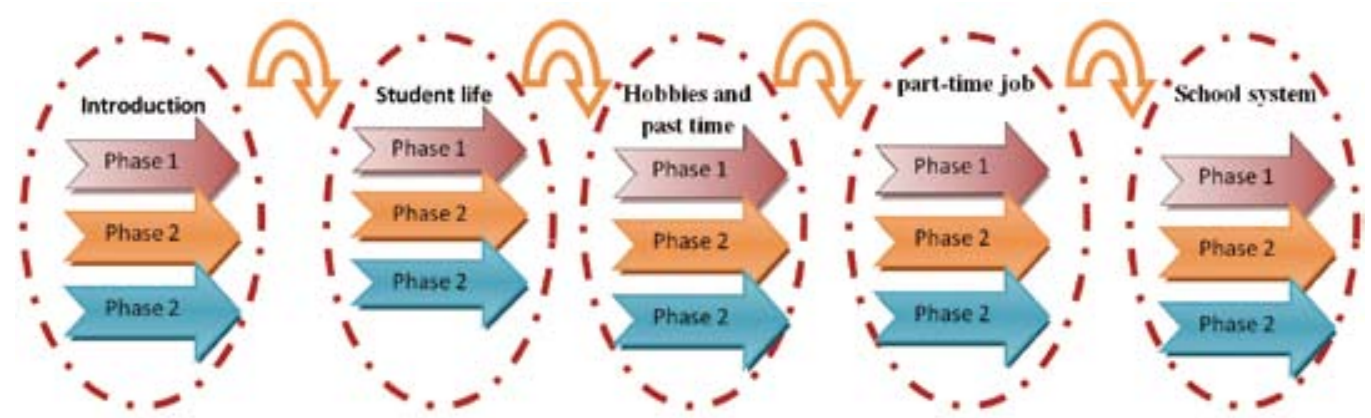

Figure 4. The cycle of the training

\subsection{Research Strategies and Data Collection Procedure}

Content analysis was applied to analyze the data collected in this study. Content analysis is used to search for patterns or themes in the text data such as interview transcriptions, diaries, or documents (Patton, 2002). To investigate pre-service teachers' strategies, documents were collected from transcriptions of screen recordings of each online session, lesson plans, and instructional PowerPoint presentations (PPTs).

Data analysis included the following process. First, the researchers coded each teacher and his/her teaching sessions. For example, T1-1 refers to teacher 1 's $1^{\text {st }}$ session. Second, the researchers randomly selected approximately two to three sessions from each topic. As a result, 13 videos were used for further analysis (T1-2, T2-3, T3-3, T4-4, T5-3, T6-1, T7-4, T8-3, T8-5, T9-2, T11-5, T12-2, and T13-1 were selected). Then, the researchers selected 15-minute long videos segments from each of the recorded videos and transcribed the segment with the support of screen capture images. Finally, the researchers compared all of the transcribed data, searched for patterns for pre-service teachers' TPCK application strategies, and analyzed the conversations between students and pre-service teachers to determine instructional appropriateness.

\section{Results}

The following section of this paper presents research results which help answer the two research questions: What instructional strategies did pre-service teachers use to transfer TPACK into practice? and Were those strategies pedagogically appropriate to teaching CFL lessons online via a videoconferencing platform?

\subsection{Instructional Strategies That the Pre- service Teachers Used}

After five training circles, pre-service teachers adopted a variety of strategies to fulfill the learners' needs and the course objectives. The following strategies were identified that were associated with using multimedia tools or videoconferencing tools.

(1)Using body language (T2-3, T3-3, T6-1, and T7-4). Body language is very important in video-conferencing lessons due to the lack of interactional context in online classes. Here, body language was referred to facial expressions and real objects used for illustration during the video chat. Although the 
CFL students could not see many movements that a teacher normally had in a traditional face-to-face classroom, the students' attention was captured and their comprehension was enhanced when their teachers used their facial expressions and utilized some real objects in the online teaching environment.

Four out of thirteen pre-service teachers used body language, including facial expressions and object illustrations in WizIQ sessions to help the students comprehend what the preservice teachers said. The following screen shots show that $\mathrm{T} 2$ was trying to explain the syntactic order of the Chinese structure (Figure 5), and T6 (Figure 6) was trying to ask a student when to sleep by using the body language.

(2) Using graphics and pictures to present information (T2-3, T5-3, T8-3, T9-2, T11-5,
T12-2, and T13-1). During the teacher training, the use of graphics and pictures were highly encouraged for developing CFL learners' speaking skills. This instructional strategy was adopted by many pre-service teachers in different situations to reach instructional purposes.

Seven out of thirteen pre-service teachers used this strategy in these two situations: initiating a conversation and introducing Chinese culture knowledge to the students. T2 (Figure 7) used graphics to ask questions about Halloween at the beginning of her session. Her students understood her speech right away without translation. T5 (Figure 8) tried to ask a student if he knew any Chinese singers and also introduced the most popular singers in Taiwan to her student by presenting photos.

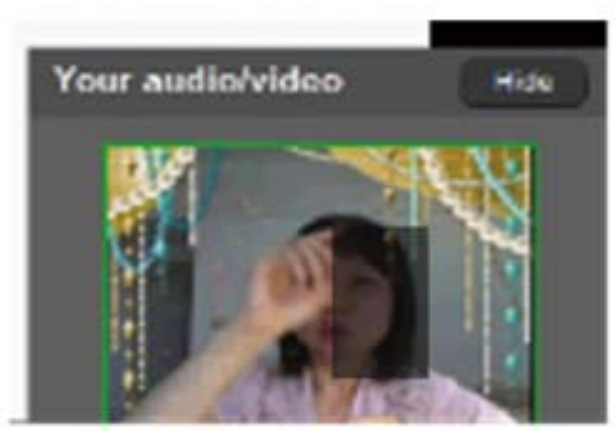

Figure 5. T2-3

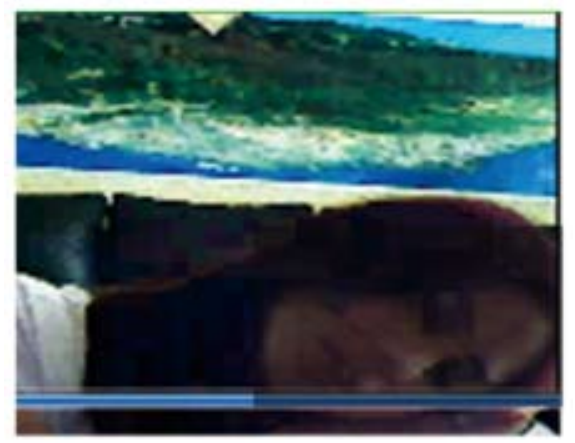

Figure 6. T6-1

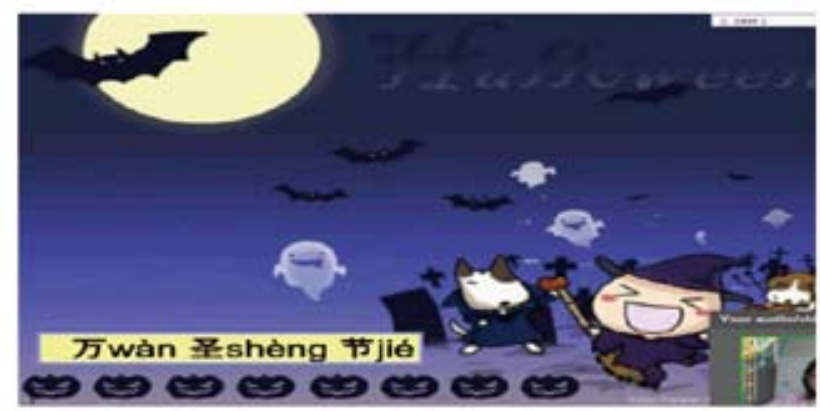

Figure 7. T2-3 


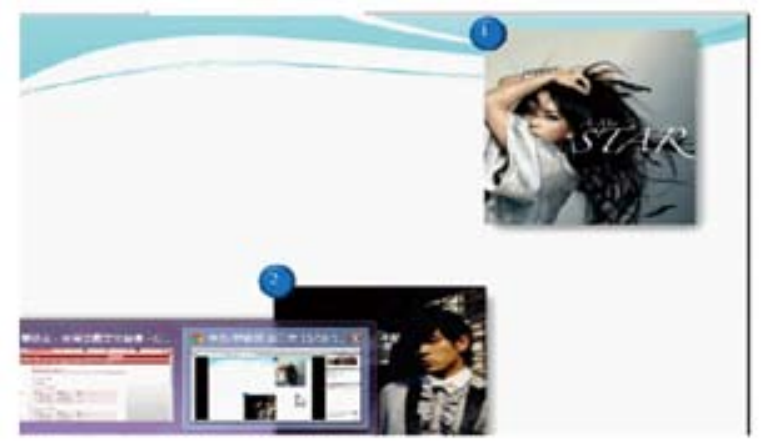

Figure 8. T5-3

(3) Using animation functions in PowerPoint presentations. This strategy was found to be commonly used in the following situations: reviewing vocabulary (T1-2, T3-3, T5-3, and T13-1), teaching new vocabulary (T1-2, T14-5, T12-2, T13-1, and T14-5), or initiating a conversation (T4-4 and T13-1). This strategy normally incorporated both graphics and the PowerPoint animation functions.

Reviewing vocabulary. T1 in Figure 9 was trying to review the vocabulary of the objects in the bathroom by first presenting the images of bathroom, and then the washer. If students did not know the answers, pre-service teachers would realize this vocabulary needed to be reviewed one more time.
Teaching new vocabulary. T13 in Figure 10 intended to talk about traditional cuisine, tofu, that the student may not know. This teacher first presented images of this dish, and then presented a flash card showing the name and the pronunciation (pinyin with tone symbols) of the dish. These illustrations allowed the student to not only see the image, but also know how to say the word correctly.

Initiating a conversation. T13 in Figure 11 was using animation functions from PowerPoint to ask students' interests at leisure time to start their conversation about hobbies and pastimes.

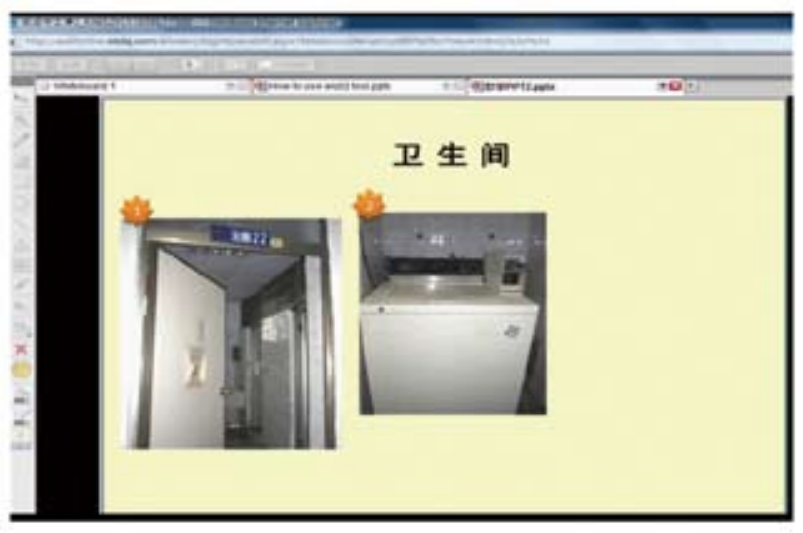

Figure 9. T1-2 


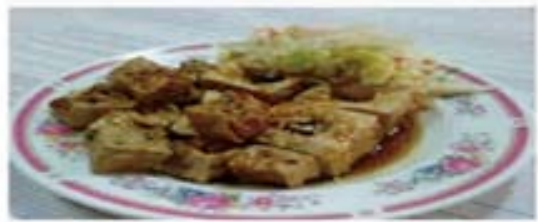

zisu chòu dòufúa

Figure 10.T13-1

(4) Using Flash and animation videos (such as Voki, GoAnimate, and Youtube) (T1-2, T2-3, T4-4, and T11-5). These resources are free online tools, and they are very easy to learn and operate in WIZIQ platform. Pre-service teachers learned how to create flash videos at stage one of the faceto-face training sessions. They integrated animated videos for listening exercises and introducing cultural information.

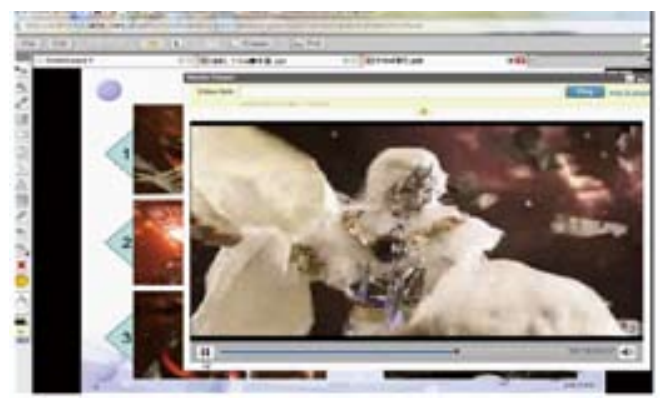

Figure 12. T2-3

(5) Using text-based input to enhance understanding (T2-3, T5-3, T6-1, T7-4, T11-5, T12-2, T13-1, and T14-5). Text inputs were adopted when reviewing the vocabulary the CFL learners learned previously, and when introducing new vocabulary for the online chat session. Three different text input methods were identified to decrease the limitation of
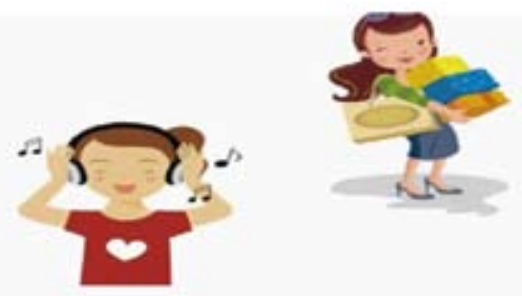

Figure 11. T13-1

To assess students listening proficiency, T4 prepared a flash animated figure talking in Chinese. Because Voki has the function of selecting different voices (young, old, male, and female), the pre-service teachers could use it to provide different audio input with different accents. When talking about the Taiwan opera (culture), a topic which students were not familiar with, T2 prepared a video clip from Youtube to allow students to experience the cultural products.

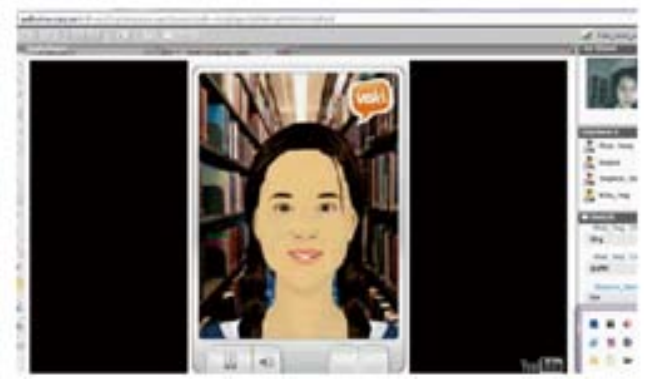

Figure 13. T4-4

Chinese input in the WizIQ whiteboard. When reviewing or introducing new vocabulary, some teachers typed both Chinese characters and phonetic symbol pinyin in the whiteboard (Figure 14); some teachers used a drawing tool to write Chinese characters with a mouse (Figure 15); and some teachers typed the characters in the text chat dialogue box. 


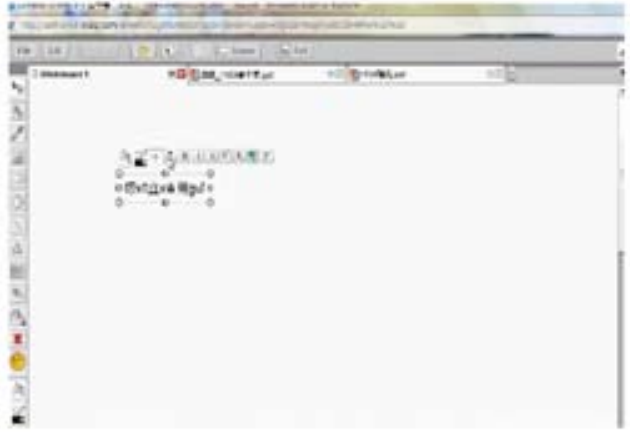

Figure 14. T2-3

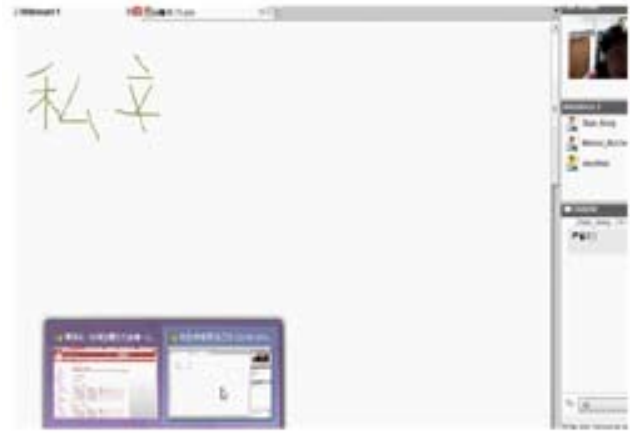

Figure 15. T5-3

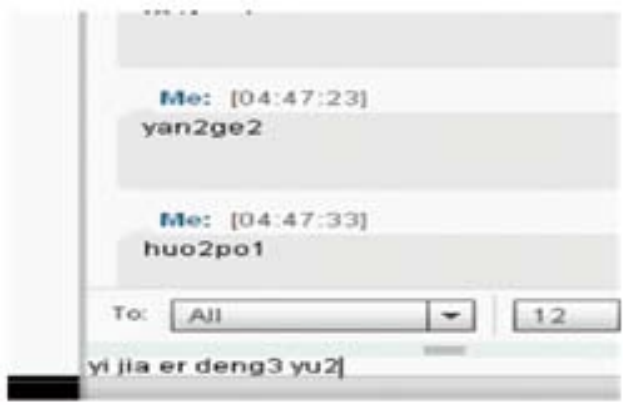

Figure 16. T7-5

\subsection{Pedagogical Appropriateness to Teaching CFL Lessons Online}

Although pre-service teachers designed and implemented a variety of technologies in teaching, some of the instructional design was not found to be appropriate for language learning. This means that pre-service teachers' TPACK were not transferred appropriately to fulfill the instructional objectives. The criteria of evaluating the appropriateness of technology uses were established based on language learners' reactions, pre-service teacher interactions, and the coherence of course content. The problems that were found in technology integration include:
Some pictures were misleading or meaningless for understanding the content (T1-2 and T9-2). Due to the lack of thoughtful consideration, some of the graphics did not convey the real meaning of what the teacher was trying to say. For example, in Figure 17, T9 was trying to introduce breakfast restaurants and Japanese restaurants, but the graphics on the PPT slide only had two entrances and the graphics did not clearly show any content related to breakfast or Japanese food. Since the CFL learners have never gone to these two restaurants in Taiwan, they would not know what types of food is offered at each restaurant. 


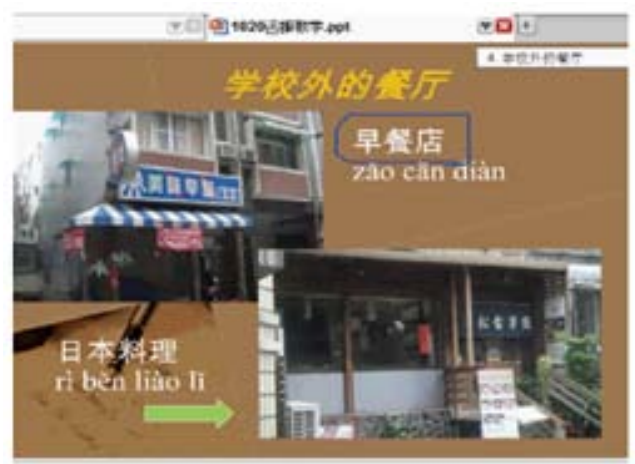

Figure 17. T9-2

Overuse of PPT animations complicated the content (T4-4). Too many animations with too many new words presented in teacher' s talk may decrease comprehension. As illustrated in the screen shot in T4-4, this teacher was planning to talk about part-time jobs. The teacher intended to ask the student if he would take a part-time job when he spent all of his money. The student's reactions to this question showed that the "carefully" designed animations and graphics did not help the student understand the teacher's intention due to the fact that the same PPT slide presented multiple graphics that seemed to the student not to be related to the part-time job.

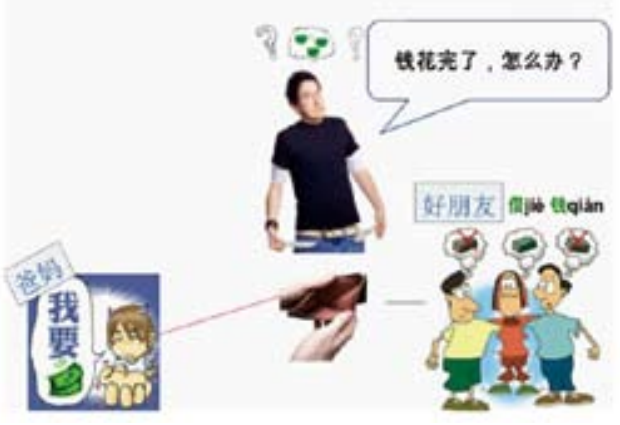

Figure 18. T4-4

Overuse of text input reduced the validity of the assessment of listening comprehension. For example, T13-1 even used pinyin to fully write the question for the student during the conversation. The student understood the question, but it was difficult to determine whether the comprehension was achieved through reading or listening. Too much text misleads the judgment of students' listening and speaking proficiency. 


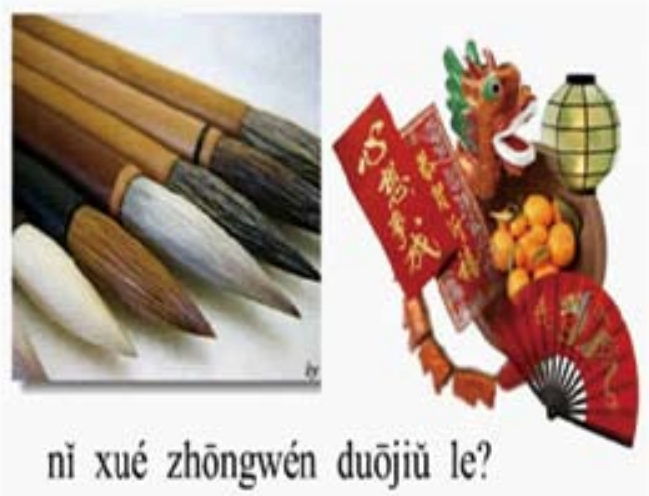

Figure 19. T13-1

\section{Discussion and Suggestions}

\subsection{Strategies that the Pre-service Teachers Used}

(1) A majority of pre-service teachers in Chinese language education are nontechnology majors, so it is very important to first teach them how to use familiar technology tools such as PowerPoint in a video-conferencing platform. In other words, their technology knowledge (TK) must be developed at the beginning of the training. When the pre-service teachers become more comfortable with the basic technology tools, the trainer teachers can demonstrate other more complicated technologies or online resources to the trainees. Once their TK becomes mature, their TPK and TCK should be trained. In this study, the instructional strategies that pre-service teachers adopted in their online instruction were considered to be the transmission of their TPACK knowledge into teaching. Through the five training cycles, the instructional strategies that the pre-service teachers used reflected their growth in TPACK training. The instructional strategies that the pre-service teachers used in teaching Mandarin Chinese were found to be helpful and meaningful for effective teaching. In particular, facial expression and body gestures are important to attract learners. When teaching Chinese language through a Web camera, pre-service teachers who used facial expressions or body gestures to convey the meaning of the conversations seemed very important

(2) The most commonly used instructional technology was to use graphics coupled with animation functions in PowerPoint for reviewing or introducing content and starting conversations. This strategy was found to be easy and effective in teaching Chinese via videoconferencing tool.

(3) Graphics and videos were found to be highly effective tools for language teachers to introduce cultural products or customs.

(4) Texting Chinese characters with phonetic symbols was an important instructional technique for students to acquire knowledge. Due to the WizIQ configuration issue, participants should 
practice WizIQ whiteboard texting before teaching the online lesson.

Obviously, among the above four instructional strategies, in this study, graphics, and flash and video clips are the most frequent technological resources that pre-service teachers used in the video-conferencing lessons. These multimedia are easy to operate and learn, so pre-service teachers often used them to initiate conversation, review or introduce vocabulary, discuss cultural topics, and assess students' listening comprehension. Regarding technology difficulties, the preservice teachers in the study seemed not to have technical issues when using these tools, except the Chinese character input issue. Therefore, most of the participants in the study could easily deliver their instruction. Nonetheless, the Chinese input techniques need to be taught and it also need to be practiced.

The instructional strategies mentioned above mostly did not require higher level computer skills. This finding implies that when providing trainings to CFL preservice teachers, the initial mission should be to help them learn to use basic and simple technological resources in their instructional design. Trendy, fancy, and complicated technologies do not need to be included in the basic technology training and those can be added as optional tools for teacher with advanced technology skills. On the other hand, it should be emphasized that pedagogy and content are equally important for pre-service teachers to consider in instructional design.

\subsection{Pedagogical Appropriateness to Teaching CFL Lessons Online}

Each technology functions differently with its own constraints and strengths. Koehler and Mishra (2009) pointed out that some technology was perfectly matched with certain instructional activity, but others were not.
This assertion shows the importance of the appropriateness of using technological tools in content with proper pedagogy. Three principles were used to determine the appropriateness of the instructional strategies that the pre-service teachers adopted in this study. The three principles are language learners' reactions, pre-service teachers' interactions, and the coherence of course content.

In this study, some technological applications were found to be inappropriate to help students reach the learning objectives. For example, overusing multimedia increased complication of information presentation. The lack of carefully selected images and pictures sometimes failed to present the meaning of new words or cultural information, and this way of using visual presentation affected the efficiency of the instruction. Overusing text input led the students to rely on the written information, rather than on listening comprehension. These inappropriately used instructional strategies maybe caused by the immature development of pre-service teachers' TPACK knowledge; the more integrated training and teaching experiences they have, the less ineffective applications may occur.

\section{Suggestions for Future Research}

This study is a preliminary study of CFL teacher training with the TPACK model. Although the findings of this research may be meaningful to CFL teacher training, three limitations constrain interpretations of the results. The three limitations include: (1) data sources were not sufficient because this study just collected data from video transcriptions, lesson plans, and PowerPoint. Technical issues caused some missing data. Interviewing and questionnaires could have been administered as data sources; (2) the CFL students' perceptions of the effectiveness of the instructional strategies that the CFL 
teachers applied to the online lesson were not investigated; and (3) the preservice teachers' technological knowledge and skills were not evaluated before the training; thus it was not possible to tell how much the pre-service teachers improved in their technology skills.

To fill the research gaps, further studies to investigate the following areas are suggested below:

(1) CFL Students' perceptions toward the training efficiency.

(2) The differences in pre-service teachers' TPACK knowledge pre- and post-training.

(3) Investigation of student teachers' teaching reflections.

(4) Further investigation of the impact of the training on pre-service teachers.

(5) Comparison of the perceptions of both students and pre-service teachers regarding the effectiveness of instructional strategies as reflected in the TPACK training model.

\section{References}

Alger, C., \& Kopcha, T. (2011). Technology supported cognitive apprenticeship transforms the student teaching field experience: Improving the student teaching field experience for all triad members. The Teacher Educator, 46, 7188.

Angeli, C., \& Valanides, N. (2009). Epistemological and methodological issues for the conceptualization, development, and assessment of ICTTPCK: Advances in technological pedagogical content knowledge (TPCK). Computers \& Education, 52(1), 154-168.

Baker, E. (2005). Can preservice teacher education really help me grow as a literacy teacher? Examining preservice teachers' perceptions of multimedia casebased instruction. Journal of Technology and Teacher Education,13(3), 415-431.

Brown, D., \& Warschauer, M. (2006). From the university to the elementary classroom: students' experiences, Journal of Technology and Teacher Education, 14(3), 599-621.

Brzycki, D., \& Dudt, K. (2005). Overcoming barriers to technology use in teacher preparation programs. Journal of Technology and Teacher Education, 13(4), 619-641.

Cantu, D. A. (2000). Technology integration in preservice history teacher education. Journal of the Association for History and Computing, 3(2), 1-19.

Cheng, H., Zhan, H., \& Tsai, D. (2010), Integrating Second Life into a Chinese language teacher training program: A pilot study, the Journal of Technology and Chinese Language Teaching (JTCLT), (1). Retrieved from http://www.tclt.us/journal/ 2010v1n1/abstract.php\#chengzhantsai

Dawson, A. (2008). Use of information communication technology by early career science teachers in western Australia. International Journal of Science Education, 30(2), 203-219.

Dawson, K. (2006). Teacher inquiry: A vehicle to merge prospective teachers experience and reflection during curriculum-based, technology-enhanced field experiences, Journal of Research on Technology in Education, 38(3), 256-292.

Fleming, L., Motamedi, V., \& May, R. (2007). Predicting preservice teacher competence in computer technology: Modeling and application in training environments, Journal of Technology and Teacher Education, 15(2), 207-231.

Fry, S.W., \& Bryant, C. (2006). Using distance technology to sustain teacher education 
for student teachers in isolated areas: The technology supported induction network. Journal of Computing in Teacher Education, 23, 63-69.

Goodson-Espy, T., Lynch-Davis, K., Schram, P., \& Quickenton, A. (2010). Using 3D computer graphics multimedia to motivate preservice teachers' learning of geometry and Padagogy. SRATE Journal, 19(2), 23-35.

Jang, S., \& Chen, K. (2010). From PCK to TPACK: Developing a transformative model for preservice science teachers. Journal of Science Education Technology, $19,553-564$.

Kay, R. H. (2006). Evaluating strategies used to incorporate technology into preservice education: A review of the literature. Journal of Research on Technology in Education, 38(4), 383-408.

Kenny, J. (2009). A partnership based approach to professional learning: Preservice and in-service teachers working together to teach primary science. Australian Journal of Teacher Education, 34(6), 1-22.

Koehler, M. J., \& Mishra, P. (2005). Teachers learning technology by design. Journal of Computing in Teacher Education, 21(3), 94-102.

Koehler, M. J., \& Mishra, P. (2009). What is technology pedagogical content knowledge? Contemporary Issues in Technology and Teacher Education, 9(1), 60-70.

Koh, J. H. L. (2011). Developing preservice teachers' technology integration expertise through the TPACK-Developing instructional model. Journal of Educational Computing Research, 44(1), 35-58.

Kumar, S., \& Vigil, K. (2011). The Net generation as preservice teachers: Transferring familiarity with new technologies to educational environments. Journal of Digital Learning in Teacher
Education, 27(4), 144-153.

O'Brien, R. (1998). An overview of the methodological approach of action research. Retrieved on August 2012 from http://www.web.ca/robrien/papers/arfinal. html

McCafferty, S. G., \& Ahmed, M. K. (2000). The appropriation of gestures of the abstract by L2 learners. In J. P. Lantolf (Ed.), Sociocultural theory and second language learning (pp. 199-218). Oxford, UK: Oxford University Press.

McKnight, A., Hoban G., \& Nielsen, W. (2011). Using Slowmation for animated storytelling to represent non-Aboriginal preservice teachers' awareness of "relatedness to country", Australasian Journal of Educational Technology, 27(1), 41-54

Shulman, L. (1986). Those who understand: Knowledge growth in teaching. Educational Researcher, 15(2), 4-14.

Sutton, S. R. (2011). The preservice technology training experiences of novice teachers. Journal of Digital Learning in Teacher Education, 28(1), 39-47.

Teclehaimanot, B., \& Lamb, A. (2005). Workshops that work! Building an effective, technology-rich faculty development program. Journal of Computing in Teacher Education, 21(3), 109-115.

Voithofer, R. (2005). Integrating servicelearning into technology training in teacher Preparation: A study of an educational technology course for preservice teachers. Journal of Computing in Teacher Education, 21(3), 103-108. (EJ882474)

Vermillion, J., Young, M., \& Hannafin, R. (2007). An academic technology initiative for teacher preparation candidates: implications for preservice teacher programs. Journal of Computing in Teacher Education, 23(3), 99-104 
Wang, S. (2012). Pedagogical Design Strategies and Practices for Online Teaching. In J. Cheng, H, Yang, \& N, Chen (Ed.) Proceedings of Educational Innovation Through Technology (EITT 2012) (pp. 493-496). USA: SICET

Wu, W.-C. V., Yen, L. L., \& Marek, M. (2011a). Using online EFL interaction to increase confidence, motivation, and ability. Educational Technology \& Society, 14 (3), $118-129$.

Wu, W.-C. V., \& Marek, M. (2011b). Making English a "habit": Increasing confidence, motivation, and ability of EFL students through cross-cultural, computer assisted interaction. The Turkish Online Journal of Educational Technology, 9(4), 101-112.

Yurdakul, I. K. (2011). An evaluative case study on professional competency of preservice information technology teachers. The Turkish Online Journal of Educational Technology, 10(3), 33-53.

\section{Acknowledgements}

This study was partially supported by the Science Council of Taiwan under the grant NSC 101-2410-H-017 -012.

\section{Contact the Authors}

Hsiu-Jen Cheng

Kaohsiung Normal University

Email: hsiujen@gmail.com

\section{Hong Zhan}

Embry-Riddle Aeronautical University

Email: zhan121@erau.edu 